\title{
高齢腹膜透析患者の身体機能・認知機能と 日常生活活動能力の特徴
}

\author{
Characteristics of Physical and Cognitive Function and Activities of Daily Living \\ of Aged Patients Undergoing Peritoneal Dialysis
}

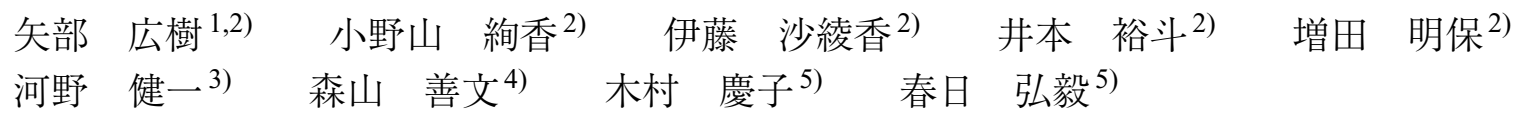

Hiroki YABE, RPT, $\mathrm{PhD}^{1,2)}$, AYAKA ONOYAMA, OTR, MS ${ }^{2)}$, SAYAKa ITO, RPT ${ }^{2)}$, Yuto IMOTO, RPT ${ }^{2)}$, AкIHo MASUDA, RPT ${ }^{2)}$, Kenichi KONO, RPT, PhD $^{3)}$, Yoshifumi MORIYAMA, HFP ${ }^{4)}$, KeIKo KIMURA, MD ${ }^{5 \text {, }}$ HiRotAKe KASUGA, MD ${ }^{5)}$

1) Department of Physical Therapy, School of Rehabilitation Sciences, Seirei Christopher University: 3453 Mikatahara-cho, Kita-ku, Hamamatsu-shi, Shizuoka 433-8558, Japan TEL+81 53-439-1400 E-mail: yabe0909@gmail.com

${ }^{2)}$ Department of Rehabilitation, Nagoya Kyoritsu Hospital

${ }^{3)}$ Department of Physical Therapy, School of Health Sciences at Narita, International University of Health and Welfare

4) Department of Wellness Center, Nagoya Kyoritsu Hospital

${ }^{5)}$ Department of Nephrology, Nagoya Kyoritsu Hospital

Rigakuryoho Kagaku 32(3): 403-407, 2017. Submitted Dec. 8, 2016. Accepted Jan. 17, 2017.

\begin{abstract}
Purpose] The objectives of this study were to measure the physical and mental functions of elderly Peritoneal dialysis (PD) patients, and to investigate their relationships with activities of daily living (ADL). [Subjects and Methods] The grip strength (GF), knee extension strength (KEF), 6-minute walking distance (6MWD), 10-meter walking speed $(10 \mathrm{mWV})$, SPPB, FIM and MMSE of 23 of PD patients aged over 65 (average age: $73.6 \pm 5.3$ years) were measured. The proportions of results below the standard level were calculated for each item, and the relationship of each item with FIM was investigated. [Results] More than half of the patients' GF, KEF and 6MWD values were lower than the standard values. Significant relationships with FIM were found for $10 \mathrm{mWV}(\mathrm{r}=0.48)$, SPPB $(\mathrm{r}=0.52)$, and MMSE $(\mathrm{r}=0.49)$. [Conclusion] The low physical function levels of the elderly PD patients in this study were related to their ADL abilities, and we consider that maintaining or raising physical function is necessary for maintaining ADL.
\end{abstract}

Key words: peritoneal dialysis, physical function, activities of daily living

要旨:〔目的〕本研究の目的は, 高齢腹膜透析患者の身体機能·認知機能を調査し, ADL との関係を検討すること.〔対 象と方法」 65 歳以上の腹膜透析患者 23 名（年齢 $73.6 \pm 5.3$ 歳）を対象に, 握力, 滕伸展筋力, 6 分間歩行距離, 10 $\mathrm{m}$ 歩行速度，SPPB，FIM，MMSE を測定し，各項目の基準值を下回る対象の割合を算出し，FIM と各指標との関 連を検討した.〔結果〕握力, 膝伸展筋力, 6 分間歩行距離は, いずれも半数以上の患者が基準值を満たさなかった. FIM 総合計は $10 \mathrm{~m}$ 歩行速度 $(\mathrm{r}=0.48), \mathrm{SPPB}(\mathrm{r}=0.52)$, MMSE $(\mathrm{r}=0.49)$ と有意な正の相関関係を認めた.〔結語〕 本調査における高齢腹膜透析患者の低い身体機能は，ADL 能力と関連しており，ADLの維持のためには身体機能の 維持・向上が必要だと考えられる。

キ一ワード : 腹膜透析, 身体機能, ADL

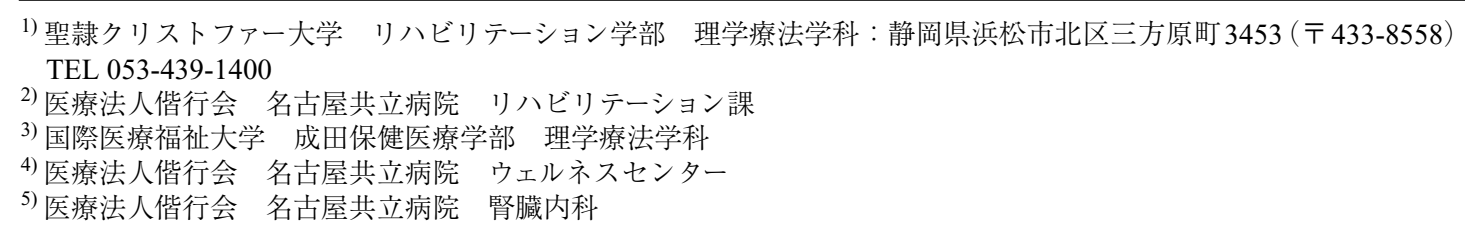




\section{I.はじめに}

本邦では透析患者の高齢化が進んでいる，日本透析医 学会の統計調査 ${ }^{1)}$ によれば, 最も透析導入の割合が高 い年齢層は男性が75-79歳で, 女性は 80-84歳であった。 今後も進行が予測される腹膜透析 (Peritoneal dialysis : 以下, PD）患者の高齢化への対策は, 必至の課題となっ ている.

近年, 在宅医療を推進する社会状況を背景に, 高齢腎 不全患者に対する PD 療法が見直されている，PDは血 液透析と比較して, 溶質と体水分の移動が緩徐であり, 病院への通院が少なくて済むという特徵 2,3) から，身体 的因子・社会的因子に拈けるメリットは高齢者において より意義が大きい 4)。一方で，高齢者に対する PD 治療 で問題となるのが，身体機能や認知機能の低下に伴う日 常生活活動（activity of daily living：以下, ADL) 能力 の低下である，高齢 PD 患者の低い身体機能や認知機能 は, 転倒や介助量の増加を介し, PD の在宅療養の妨げ になる可能性がある。しかしながら，PDは慢性腎不全 患者に対して血液透析の導入前の治療として用いられて いたという経緯から，高齢の腹膜透析患者における検討 が進んでいない，本研究の目的は，高齢 PD患者の身体 機能と認知機能を横断的に評価し, ADL との関連を明 らかにすることで, 高齢 PD 患者の病態を身体機能面と $\mathrm{ADL}$ 面から提言することである.

\section{II. 対象と方法}

\section{1. 対象}

対象は, 当院 PD 外来通院中で, PD 治療を施行中の 65 歳以上の患者 23 名 (年齢 $73.6 \pm 5.3$ 歳, 男性 8 名, 女性 15 名, BMI $22.9 \pm 2.6 \mathrm{~kg} / \mathrm{m}^{2}, \mathrm{PD}$ 歴 $39.6 \pm 29.4$ 力 月）とした（表 1).

\section{2. 方法}

評価は腹膜透析外来の待ち時間に当院のリハビリテー ション室で実施した。身体機能の評価は理学療法士が行 い, 膝伸展筋力は筋力計 (ミュータス F-1，アニマ社製) 握力, 6 分間歩行距離, 総合的な身体機能として Short physical performance battery（SPPB）を測定し, 滕伸展 筋力は体重で除した比率を解析した，握力は右上肢にて 測定した. ADLは Functional independent measure（以下 FIM), 認知機能は Mini Mental State Examination（以下, MMSE）を用いて測定した. 各測定項目の平均值は, 先 行研究 5-10) で示されている基準值と比較すると同時に, 各指標の基準值を下回る対象の割合を算出した. 6 分間 歩行距離は, 文部科学省の統計調査 ${ }^{5)}$ による年齢別の 平均值から, 統計的に外れ值と判断できる平均值 - (2 ×標準偏差）以下を低下ありとした。握力, $10 \mathrm{~m}$ 歩行
表 1 対象者属性

\begin{tabular}{lc}
\hline 年齢 & $73.6 \pm 5.3$ 歳 \\
性別 (男/女) & $8 / 15$ 人 \\
身長 & $156.3 \pm 9.1 \mathrm{~cm}$ \\
体重 & $58.2 \pm 8.9 \mathrm{~kg}$ \\
$\mathrm{BMI}$ & $22.9 \pm 2.6 \mathrm{~kg} / \mathrm{m}^{2}$ \\
腹膜透析歴 & $39.6 \pm 29.4$ 力 \\
腹膜透析 /血液透析併用 & 0 人 \\
原疾患 & \\
慢性糸球体腎炎 & 6 人 $(26.1 \%)$ \\
腎硬化症 & 4 人 $(17.4 \%)$ \\
糖尿病性腎症 & 9 人 $(39.1 \%)$ \\
その他 & 4 人 $(17.4 \%)$ \\
基礎疾患 & \\
糖尿病 & 14 人 $(60.9 \%)$ \\
高血圧 & 22 人 $(95.7 \%)$ \\
脂質異常症 & 19 人 $(82.6 \%)$ \\
心疾患の既往 & 5 人 $(21.7 \%)$ \\
血液デー夕 & \\
TP & $6.7 \pm 0.6 \mathrm{~g} / \mathrm{dl}$ \\
$\mathrm{Alb}$ & $3.2 \pm 0.4 \mathrm{~g} / \mathrm{dl}$ \\
$\mathrm{BUN}$ & $57.6 \pm 14.8 \mathrm{mg} / \mathrm{dl}$ \\
$\mathrm{Cr}$ & $9.4 \pm 2.9 \mathrm{mg} / \mathrm{dl}$ \\
$\mathrm{eGFR}$ & $4.9 \pm 1.7 \mathrm{ml} / \mathrm{min}$ \\
$\mathrm{Hb}$ & $11.5 \pm 1.2 \mathrm{~g} / \mathrm{dl}$ \\
$\mathrm{Ht}$ & $35.9 \pm 3.6 \%$ \\
\hline
\end{tabular}

平均値 \pm 標準偏差. $\mathrm{TP}$ : 総蛋白, $\mathrm{Alb}$ : 血清アルブミン 值, $\mathrm{Cr}$ ：クレアチニン, BUN : 尿素窒素, eGFR : 推定 糸球体濾過量, $\mathrm{Hb}$ ：ヘモグロビン, $\mathrm{Ht}$ ：ヘマトクリット.

速度, SPPBは Asian working group for sarcopeniaによ り身体機能低下ありと判定される值を用いた（握力：男 性 $26 \mathrm{~kg}$ 未満, 女性 $18 \mathrm{~kg}$ 未満, $10 \mathrm{~m}$ 歩行速度 : $0.8 \mathrm{~m} /$ $\mathrm{s}$ 未満, SPPB : 8 点未満) 6. 膝伸展筋力は, 先行研究 から, 正常歩行に必要な筋力水準 7) や, 高齢入院患者 の院内歩行自立が阻害されはじめる筋力水準 ${ }^{8)}$ がいず れも $40 \%$ と報告されていることから，体重比の $40 \%$ 末 満を低下ありとした ${ }^{9}$. MMSE は，23 点以下を認知症 の疑いありとして解析した ${ }^{10)}$. FIM は，下位項目のい ずれかひとつでも 5 点以下（介助者による監視・準備を 必要とする) を有する場合，合計点に関わらず低下あり とした。

統計的検討は統計解析ソフト (SPSS Statistics22, IBM 社製）を用い, FIM の総合計点, 運動項目合計点, 認 知項目合計点のそれぞれと各指標との関連をPeasonの 相関倸数により検討した，有意水準は $5 \%$ とした。

倫理的配慮として, 本研究は名古屋共立病院の倫理委 員会の承認のもと，患者には口頭および書面にて説明し， 同意を得て実施した（K091-01）。 
表 2 高齢腹膜透析患者の身体機能と基準值との比較

\begin{tabular}{|c|c|c|c|}
\hline & 平均值 \pm 標準偏差 & 基準值 & $\begin{array}{c}\text { 基準值以下 } \\
\text { 人 (\%) }\end{array}$ \\
\hline 握力 $(\mathrm{kg})$ & $24.2 \pm 7.6$ & 男性 $<26 \mathrm{~kg}$ ，女性 $<18 \mathrm{~kg}$ & $12(52.2)$ \\
\hline 膝伸展筋力（％） & $37.0 \pm 9.6$ & $<40 \%$ & $15(68.2)$ \\
\hline 6 分間歩行距離 $(\mathrm{m})$ & $362.9 \pm 100$ & 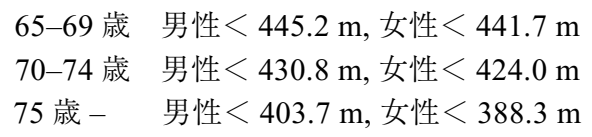 & $16(69.6)$ \\
\hline $10 \mathrm{~m}$ 歩行速度 $(\mathrm{m} / \mathrm{s})$ & $1.1 \pm 0.2$ & $<0.8 \mathrm{~m} / \mathrm{s}$ & $3(13.0)$ \\
\hline SPPB（点） & $10.7 \pm 1.8$ & $<8$ 点 & $4(17.4)$ \\
\hline MMSE（点） & $26.2 \pm 2.9$ & $<24$ 点 & $4(17.4)$ \\
\hline FIM（点） & $124.1 \pm 3.1$ & 5 点以下の下位項目を一つでも含む場合 & $3(13.0)$ \\
\hline
\end{tabular}

SPPB : Short physical performance battery, MMSE : Mini Mental State Examination, FIM : Functional independent measure.

\section{III. 結 果}

各身体機能の測定值を表 2 に示す，対象の握力の平均 は $24.2 \pm 7.6 \mathrm{~kg}$ であり，12名（52.2\%）の患者で基準 值を満たしていなかった，膝伸展筋力も同様に，平均值 は $37.0 \pm 9.6 \%$ ありり，15名（68.2\%）の患者で基準 值を満たしていなかった。 6 分間歩行距離の平均は $362.9 \pm 100 \mathrm{~m}$ であり，16 名（69.6\%）の患者で低下を 認めた。一方, 歩行速度 $(1.1 \pm 0.2 \mathrm{~m} / \mathrm{s})$, SPPB $(10.7$ \pm 1.8 点), MMSE (26.2 \pm 2.9 点), FIM (124.1 \pm 3.1 点）に関しては，先に述べた身体機能の項目と比べて基 準值を下回る患者の割合は低く，それぞれ 3 名 $(13.0 \%), 4$ 名 $(17.4 \%), 4$ 名 $(17.4 \%), 3$ 名 $(13.0 \%)$ であったままた FIMの下位項目のうち，介助者を必要 とする ADL 動作（FIM で 5 点以下）は，排便管理，入 浴動作, 認知項目 (理解と記憶) であった.

FIM と各指標の関係を検討した結果，FIM 総合計は $10 \mathrm{~m}$ 歩行速度 $(\mathrm{r}=0.48)$, SPPB $(\mathrm{r}=0.52)$, MMSE $(\mathrm{r}=0.49)$ と有意な正相関を認めた $(\mathrm{p}<0.05)$. FIM の 運動項目の合計は, 6 分間歩行距離 $(\mathrm{r}=0.47), 10 \mathrm{~m}$ 歩 行速度 $(r=0.56), \operatorname{SPPB}(r=0.57), \operatorname{MMSE}(\mathrm{r}=0.46)$ と有意な正相関を認めた $(\mathrm{p}<0.05) （$ 表 3$)$.

\section{IV. 考 察}

本調査の高齢 PD 患者は，身体機能が各種の基準值よ り低く，半数以上が基準值を満たしていなかった。腹膜 透析患者は，透析を受けていない同年代の慢性腎不全患 者よりも骨格筋菱縮がみられると報告されている ${ }^{11)}$. 末期腎不全患者における骨格筋減少は, 栄養指標 ${ }^{12)}$ は もちろん，尿毒症性ミオパチーによる骨格筋の酸素利用 能の低下, ミトコンドリア数の減少や毛細血管密度の低 下，筋内脂肪浸潤が関与し ${ }^{13)}$ ，筋内脂肪浸潤か進んた
表 3 高齢腹膜透析患者の FIM と身体機能・認知機能との 相関係数

\begin{tabular}{lccc}
\hline & 総合計 & 運動合計 & 認知合計 \\
\hline 年齢 & -0.12 & -0.21 & 0.04 \\
BMI & 0.21 & 0.27 & -0.01 \\
腹膜透析歴 & 0.18 & 0.23 & 0.04 \\
握力 & 0.29 & 0.39 & -0.05 \\
膝伸展筋力 & 0.28 & 0.3 & 0.16 \\
6 分間歩行距離 & 0.45 & $0.47^{*}$ & 0.12 \\
$10 \mathrm{~m}$ 歩行速度 & $0.48^{*}$ & $0.56^{*}$ & -0.16 \\
$\mathrm{SPPB}$ & $0.52^{*}$ & $0.57^{*}$ & 0.26 \\
$\mathrm{MMSE}$ & $0.49^{*}$ & $0.46^{*}$ & $0.45^{*}$ \\
\hline
\end{tabular}

$*: \mathrm{p}<0.05$. 略称は表 2 と同様.

症例では，慢性炎症の併存 14)も指摘されており，高齢 PD 患者は身体機能が低下しやすい病態にあると考えら れる。

筋力の指標である握力と膝伸展筋力は, 半数以上の患 者で基準値を下回っていた．筋力は加齢に伴う骨格筋量 の減少によって低下するが, 高齢の地域在住高齢者（平 均年齢 70.5 歳, 膝伸展筋力 $60.2 \%$ ） 15) と比較し維持血 液透析患者（平均年齢 64 歳, $40.7 \%$ ） 9) は低值であると 報告されている. 本研究の膝伸展筋力の結果は $37 \%$ で あり, 高齢 PD 患者は先行研究と比較しても下肢筋力が 低い患者群であるといえる。 また握力は，男性では 26 $\mathrm{kg}$ 未満で 7.6 倍, 女性では $16 \mathrm{~kg}$ 未満で 4.4 倍の確率で 歩行障害が存在すること ${ }^{16)}$ や，末期腎不全患者の腎予 後を予測すること ${ }^{17)}$ が報告されている，筋力や体力が 低下している高齢 PD 患者に扔ける身体機能の向上は, 重要な課題であると考えられる.

6 分間歩行距離は, 最大酸素摂取量と高い相関を示す ことから ${ }^{18-21)}$ ，体力を簡便に測定する指標として用いら れる. さらに血液透析患者の 6 分間歩行テストの要因に 
は，膝伸展筋力に加え総鉄結合能や冠動脈疾患の有無が 影響すること 22)や, Continuous Ambulatory Peritoneal Dialysis（以下, CAPD）患者の最高酸素摂取量には細 胞外液 /内液比が関連すること ${ }^{23)}$ が報告されている. 今回の結果から高齢 PD 患者 6 分間歩行距離が低值とな る原因は特定できないが, 体力に加え心疾患や貧血, 体 液貯留が関与している可能性がある.

6 分間歩行距離の基準值に関しては, 地域在住高齢者 の転倒群 $(341 \mathrm{~m})$ は非転倒群 $(416 \mathrm{~m})$ よりも有意に 低いこと 24)や，6分間歩行距離が $390 \mathrm{~m}$ 未満の慢性心 不全患者は, 再入院率が有意に高いこと ${ }^{25)}$, 血液透析 患者における 6 分間歩行距離の $20 \mathrm{~m}$ の増加は, 全死亡, 心血管死亡，入院リスクの低下と関連すること 26) が報 告されている. 本研究の結果から, 高齢 PD患者は転倒 リスクを有する地域在住高齢者や, 心疾患を有する症例 や血液透析患者と同等か，それ以上に体力レベルが低く， 入院や転倒などのリスク発生の危険性が高い患者群であ ると考えられる。

$10 \mathrm{~m}$ 歩行速度と SPPB, FIM の結果は, 体力や筋力 と比して基準值を下回る対象が少なかった。特に FIM について，血液透析患者の FIMに関する報告では，外 来血液透析患者 (31 例, 年齢 $64 \pm 12$ 歳) のFIM が 123 点であったと報告されており27), 本研究の対象は 先行研究よりも高齢であるにもかかわらず, 先行研究と 同程度の FIM であった。 65 歳以上の地域在住高齢者を 対象とした ADLの調査結果では, 歩行, 階段, 基本動作, 更衣，入浴が難易度の高い ADLであるとされており28) 今後は高齢 PD 患者においても上記 ADL の低下を予防 する必要があると考えられる。また本症例群の FIM は, 6 分間歩行距離, $10 \mathrm{~m}$ 歩行速度, SPPB に加え, MMSE とも関連を認めた。先行研究では日本人における ADL 障害をきたす原因疾患は認知症が最も高いこと29)や, 高齢 PD 患者 19 名の縦断的な観察によって, 死亡率は 体重減少と腹膜機能に加え, 認知機能が関係すること 30)が示されている。また 75 歳以上の患者における CAPDの継続を困難にする理由として, 身体機能の低

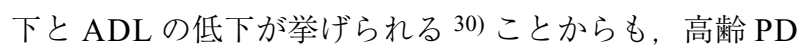
患者の ADLは, 身体機能や認知機能が影響し, 種々の 身体機能によって複合的に支えられていると考えられる.

高齢 PD 患者の問題点を把握するためには，身体・精 神心理・家庭・社会的側面を含む包括的な検討が必要で ある 4)。身体機能や ADLの低下に伴い, 日常生活だけ でなくPDの管理が自立困難となった場合, 家族指導や サービス資源の使用などの対策を追加する必要があり, さらに将来的に PD離脱のリスクも増加する. 高齢 PD 患者の在宅療養の長期にわたる継続のためには, 身体機 能とADL を維持するための評価と介入を，医師，看護師， 薬剤師, 管理栄養士に加え, リハビリテーション関連職 種を含む多職種で連携して行う必要があると考えられる。

\section{引用文献}

1)（一社）日本透析医学会統計調査委員会：図説わが国の慢 性透析療法の現況. http://docs.jsdt.or.jp/overview/（閲覧日 2016年11月 1 日).

2) Brown EA: Peritoneal dialysis in the elderly. Contrib Nephrol, 2009, 163: 264-269.

3) Brown EA, Johansson L, Farrington K, et al.: Broadening Options for Long-term Dialysis in the Elderly (BOLDE): Differences in quality of life on peritoneal dialysis compared to haemodialysis for older patients. Nephrol Dial Transplant, 2010, 25: 3755-3763.

4) 古賀祥嗣, 平松 信, 中山昌明 - 他 : 高齢者腹膜透析患者 の予後と影響因子に関する多施設共同前向き研究—高齢者 腹膜透析研究会（ゼニーレPD研究会）中間報告一. 日本透 析医学会雑誌, 2007, 40: 161-167.

5) 文部科学省 : 平成 26 年度体力 - 運動能調査. http://www.estat.go.jp/SG1/estat/NewList.do?tid=000001016672（閲覽日 2016年11月 1 日).

6) Chen LK, Liu LK, Woo J, et al.: Sarcopenia in Asia: Consensus report of the Asian Working Group for Sarcopenia. J Am Med Dir Assoc, 2014, 15: 95-101.

7) 黄川照雄, 山本利春, 佐々木敦之 - 他 : 機能的筋力測定 評価法一体重支持指標（WBI）の有効性と評価の実際。整形 外科スポーツ医学会誌, 1991, 10: 463-468.

8) 西島智子, 小山理惠子, 内藤郁奈・他：高齢患者に扔け る等尺性膝伸展筋力と歩行能力との関係. 理学療法科学, 2004, 19: 95-99.

9) Matsuzawa R, Matsunaga A, Wang G, et al.: Relationship between lower extremity muscle strength and all-cause mortality in Japanese patients undergoing dialysis. Phys Ther, 2014, 94: 947-956.

10) 日本神経学会 (監修) : 日本認知症疾患治療ガイドライン 2010. https://www.neurology-jp.org/guidelinem/degl/sinkei_ deg1_2010_03.pdf（閲覧日2016年11月1日）.

11) McIntyre CW, Selby NM, Sigrist M, et al.: Patients receiving maintenance dialysis have more severe functionally significant skeletal muscle wasting than patients with dialysis-independent chronic kidney disease. Nephrol Dial Transplant, 2006, 21: 2210-2216.

12) 伊藤晃範, 熟頭由宜, 林 大二郎 - 他：血液透析患者の筋 肉量と筋力に与える因子. 北海道理学療法, 2011, 28: 3842.

13) Sakkas GK, Kent-Braun JA, Doyle JW, et al.: Effect of diabetes mellitus on muscle size and strength in patients receiving dialysis therapy. Am J Kidney Dis, 2006, 47: 862-869.

14) Cheema $B$, Abas $H$, Smith $B$, et al.: Investigation of skeletal muscle quantity and quality in end-stage renal disease. Nephrology (Carlton), 2010, 15: 454-463.

15) Yamamoto $S$, Matsunaga A, Kamiya K, et al.: Walking speed in patients with first acute myocardial infarction who participated in a supervised cardiac rehabilitation program after coronary intervention. Int Heart J, 2012, 53: 347-352.

16) Alley DE, Shardell MD, Peters KW, et al.: Grip strength cutpoints for the identification of clinically relevant weakness. J Gerontol A Biol Sci Med Sci, 2014, 69: 559-566.

17) Chang YT, Wu HL, Guo HR, et al.: Handgrip strength is an in- 
dependent predictor of renal outcomes in patients with chronic kidney diseases. Nephrol Dial Transplant, 2011, 26: 35883595.

18) Peeters P, Mets T: The 6-minute walk as an appropriate exercise test in elderly patients with chronic heart failure. J Gerontol A Biol Sci Med Sci, 1996, 51: M147-M151.

19) Pulz C, Diniz RV, Alves AN, et al.: Incremental shuttle and six-minute walking tests in the assessment of functional capacity in chronic heart failure. Can J Cardiol, 2008, 24: 131135.

20) Morales FJ, Martínez A, Méndez M, et al.: A shuttle walk test for assessment of functional capacity in chronic heart failure. Am Heart J, 1999, 138: 291-298.

21) Riley M, McParland J, Stanford CF, et al.: Oxygen consumption during corridor walk testing in chronic cardiac failure. Eur Heart J, 1992, 13: 789-793.

22) Kono K, Nishida $Y$, Moriyama $Y$, et al.: Investigation of factors affecting the six-minute walk test results in hemodialysis patients. Ther Apher Dial, 2014, 18: 623-627.

23) Zuo ML, Yue WS, Yip T, et al.: Prevalence of and associations with reduced exercise capacity in peritoneal dialysis patients. Am J Kidney Dis, 2013, 62: 939-946.

24) 高野映子, 渡辺豊明, 寺西利生 - 他：健常な地域在住高齢 者における転倒を予測する評価の検討一文部科学省新体力
テストの結果を用いて一. 日本転倒予防学会, 2014, 1: 2128.

25) Tabata M, Shimizu R, Kamekawa D, et al.: Six-minute walk distance is an independent predictor of hospital readmission in patients with chronic heart failure. Int Heart J, 2014, 55: 331336.

26) Guralnik JM, Ferrucci L, Pieper CF, et al.: Lower extremity function and subsequent disability: Consistency across studies, predictive models, and value of gait speed alone compared with the short physical performance battery. J Gerontol A Biol Sci Med Sci, 2000, 55: M221-M231.

27) 米須 功, 儀間朝次, 渡嘉敷秀夫 - 他 : 入院透析患者に 扔けるADLの検討. 日本透析医学会雑誌, 2009, 42: 939945.

28) Yoshida D, Ninomiya T, Doi Y, et al.: Prevalence and causes of functional disability in an elderly general population of Japanese: The Hisayama study. J Epidemiol, 2012, 22: 222-229.

29）下村 旭，田原大悟，畦倉久紀：CAPDによる高齢透析患 者（75歳以上）の治療成績と問題点一脱落の要因に関する検 討. 日本透析医学会雑誌, 1994, 27: 27-34.

30) 遠藤智江, 吉田潤子, 濱 初子： 75 歳以上高齢者に対す るCAPDの現状と今後の課題. Tokushima Red Cross Hosp Med J, 2011, 16: 16-20. 